\section{Obesity, Lung Cancer, And The Paradox Of Its Association: A Narrative Review}

\section{DOI: 10.52629/jamsa.v9i1.257}

Background The obesity rate in Indonesia always increases every year. RISKESDAS (Indonesian National Health Research Data) 2007, 2013, and 2018 showed that the obesity rate is always increasing in Indonesia. Lung cancer is the most common cancer in Indonesia which causes death.

Objective This review aims to explain various diseases which are associated with obesity, risk factors of lung cancer, and the association between them

Methods A literature search was conducted in PubMed and textbooks regarding obesity and lung cancer risk factors. The literature search on the association between obesity and lung cancer was done in PubMed with the keyword "(Lung Cancer [Title]) AND (Obesity [Title])".

Results Based on the research conducted, it was found that obesity was associated with various diseases including type 2 diabetes, dyslipidemia, cancer risk, mood disorders, heart disease, hypertension, liver disease, and reproductive disorders. Furthermore, there are various risk factors for lung cancer, including gender, genetics, tobacco use, and exposure to toxic agents. The association between obesity and lung cancer is a paradoxical phenomenon that occurs, in which obese patients have a lower risk of developing lung cancer based on the meta-analysis research (RR: 0.79; 95\% Cl 0.73-0.85).

Conclusion Current clinical research studies have shown that obesity reduces the risk of lung cancer, especially in smokers. Thus, we suggest further experimental research either in clinicals or laboratories about the biological mechanisms that can explain this phenomenon. Regardless of this paradoxical
Kemal Akbar

Suryoadji', Jason

Theola', Valentino Ryu

Yudianto'

${ }^{1}$ Faculty of Medicine, Universitas Indonesia

Correspondence to: Kemal Akbar Suryoadji Faculty of Medicine, Universitas Indonesia

kemalakbar11@gmail.com 
association, we also suggest that the public should continue to control body weight because of the risk of various diseases associated with obesity.

Keywords lung cancer, obesity, obesity paradox 
102 Suryoadji et al: Obesity, Lung Cancer, And The Paradox Of Its Association:

\section{Introduction}

RISKESDAS (Indonesian National Health Research Data) 2018 data showed that there was an increase in the number of overweight and obese adults in Indonesia compared to 2007 and 2013 RISKESDAS. Overweight and obesity are measured with body mass index (BMI) by dividing body weight in kilograms and height squared in centimeters (with units of $\mathrm{kg} /$ $\left.\mathrm{m}^{2}\right)^{2}{ }^{2}$ The IMT range 25.0-26.9 is considered overweight and $\geq 27.0$ is considered obese. The overweight population in 2013-2018 increased from $11.5 \%$ to $13.6 \%$. Meanwhile, the adult population with obesity increased from $14.8 \%$ to $21.8 \%$, which can increase the risk of various diseases.

Cancer is the leading cause of death in the world. Based on 2012 WHO data, the most common cancer diagnosed in men is lung cancer, which is $16.8 \%$ of all cancers. In women, it ranks second after breast cancer with $12 \%$ of all cancers. ${ }^{3}$ Also, lung cancer is known as the leading cause of death in the world. ${ }^{4}$

Data in Indonesia based on a report from the Department of Pulmonology and Respiratory Medicine FKUI at the Persahabatan Hospital in 2015 revealed that $88.4 \%$ of existing thoracic oncology cases were lung cancer. ${ }^{5}$ The Indonesian cancer profile based on cancer country profiles made by WHO in 2014 showed that the incidence of lung cancer in men ranked first with cancer, with 25,322 cases and the incidence of lung cancer in women ranks fifth, with 9,372 cases. $^{6}$

Based on the data presented earlier, it is known that both obesity and lung cancer have a high incidence rate. However, several studies demonstrate that obesity can reduce the risk of developing lung cancer. This is an interesting finding for the authors to find out more about how two negative medical conditions have a negative correlation. Therefore, besides examining the risk factors for obesity and lung cancer, the authors would like to demonstrate the evidence related to obesity which can reduce the risk of lung cancer.

\section{Methods}

Diseases due to obesity and risk factors for lung cancer were traced manually in various credible medical textbooks and from various journals in PubMed or NCBI in a comprehensive manner. The discussion of literature was carried out through the PubMed search channel in the advance search with the keyword "(Lung Cancer [Title]) AND (Obesity [Title])" and found 42 research studies from all over the world. Furthermore, the authors conducted a review of all studies to determine research studies that discuss obesity as a risk factor for lung cancer as a type of etiological study that followed up the patients from before and after being diagnosed with lung cancer. The author also excluded prognostic studies in patients who had been diagnosed with lung cancer from the beginning of the study and also excluded research studies that could not be accessed in full text and were not written in English. Furthermore, 2 articles are most considered to show the relationship between obesity and lung cancer. 


\section{Results}

Obesity and its Relationship with Various Diseases

Obesity is characterized by an excess increase in the body mass index of a person with different criteria between the European population and the Asia Pacific population, including Indonesia.7,8 The difference in the Body Mass Index (BMI) criteria number between $\mathrm{WHO}$ and the Asia Pacific can be seen in table 1.

Table 1. Differences in WHO Body Mass Index Classification with Asia

\begin{tabular}{|l|l|l|}
\hline Classification & $\begin{array}{l}\text { Asia Pasific } \\
\text { (BMI) }\end{array}$ & $\begin{array}{l}\text { WHO } \\
\text { (BMI) }\end{array}$ \\
\hline Underweight & $<18,5$ & $<18,5$ \\
\hline Normal & $18,5-22,9$ & $18,5-24,9$ \\
\hline Overweight & $23,0-24,9$ & $25,0-29,9$ \\
\hline Obesity grade 1 & $25-29,9$ & $30-24,9$ \\
\hline Obesity grade 2 & $\geq 30$ & $35,0-39,9$ \\
\hline Obesity grade 3 & - & $\geq 40$ \\
\hline
\end{tabular}

Based on the BMI classification in the Asia Pacific population, it shows that a BMI of more than 25 is considered obese.8 Therefore, in the RISKESDAS data referring to the Asia Pacific BMI guidelines, the excess weight in the 2018 RISKESDAS data also includes the obesity population because the BMI value has exceeded 25 $\mathrm{kg} / \mathrm{m} 2$.

Diseases or disorders that can be caused by obesity can be seen in Figure 1. Among them are type 2 diabetes mellitus, dyslipidemia, risk of cancer, mood disorders, heart disease, hypertension, liver disease, and reproductive disorders. ${ }^{9-15}$

Malone et al (2019) suggest that obesity at a young age can increase the risk of type two diabetes mellitus later in life. In addition, the relationship between the two aspects is a two-way relationship between obesity which is the cause of type two diabetes, and vice versa. ${ }^{9}$

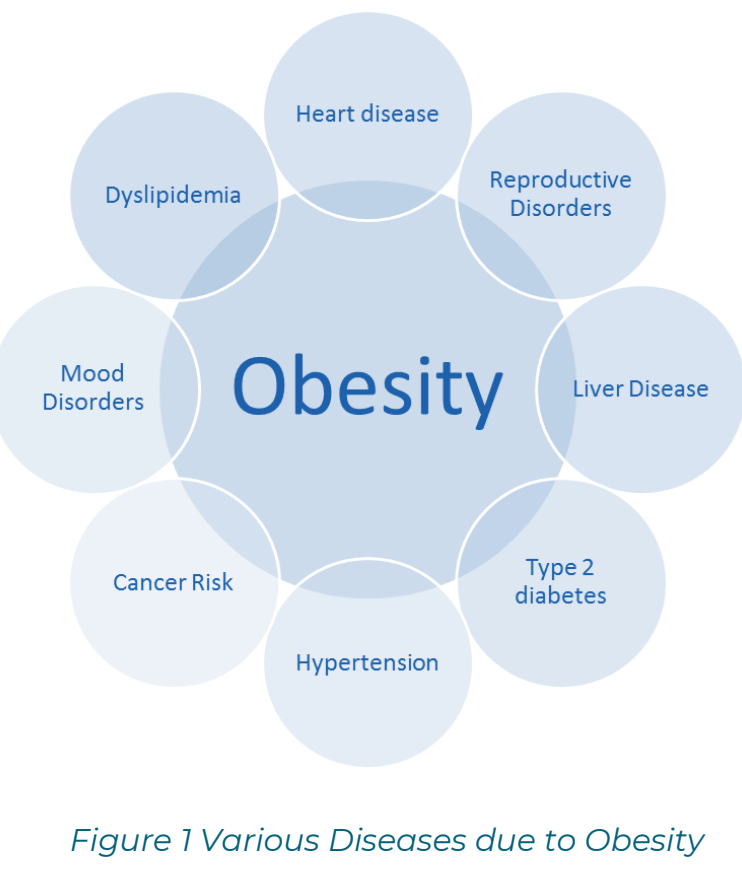

Obesity can also affect the occurrence of dyslipidemia, as stated by Vekic et al (2019), one of which is the PCSK9 proprotein mechanism which regulates the increase in LDL lipoproteins. It is also associated with the obesity mechanism which causes the effects of insulin resistance and proinflammatory adipokines. ${ }^{10}$

Cancer risk can also arise due to obesity which occurs in various mechanisms. Based on Avgerinos et al (2018), various mechanisms of obesity that increase cancer risk include insulin resistance, system abnormalities, and IGF-I signaling, sex hormone biosynthesis and pathways, chronic inflammation and oxidative stress, changes in adipokine pathophysiology, and factors derived from ectopic fat buildup. However, in various cancers, there 
is a paradox that obesity reduces its risk, such as in lung cancer when research is conducted."

Mood disorders can also be associated with obesity. A review by Soczynska et al (2010) explains that both mood disorders and obesity can cause abnormalities in physiological interactions such as insulin signaling, counter-regulation, and immune-inflammatory hormones. ${ }^{12}$

Hypertension and heart disease are also higher in obese patients, as stated by Saliba et al (2019). Also, non-alcoholic fatty liver disease, which is the most common liver disease, is more often experienced by obese patients according to Corey et al $(2014))^{13-14}$

The high incidence number of obesity both in Indonesia and in the world is often referred to as an epidemic in the modern world or an epidemic in the $27^{\text {st }}$ century. Obesity also has many relationships with various diseases of various organ systems that have already been described.

\section{Risk Factors for Lung Cancer}

Various risk factors can affect the increasing potential for developing lung cancer. Among them are gender, genetics, tobacco use, and exposure to toxic agents..$^{16}$ These risk factors can be seen in

\section{Figure 2.}

White et al (2014) revealed that age over 40 increases the risk of lung cancer and increases with each additional age. The process that is thought to underlie this condition is the aging process which continues to undergo genetic mutations. The genetic mutation process affects a normal cell in its development into cancer cells due to DNA damage over time and disruption of normal cell repair and growth. ${ }^{17}$

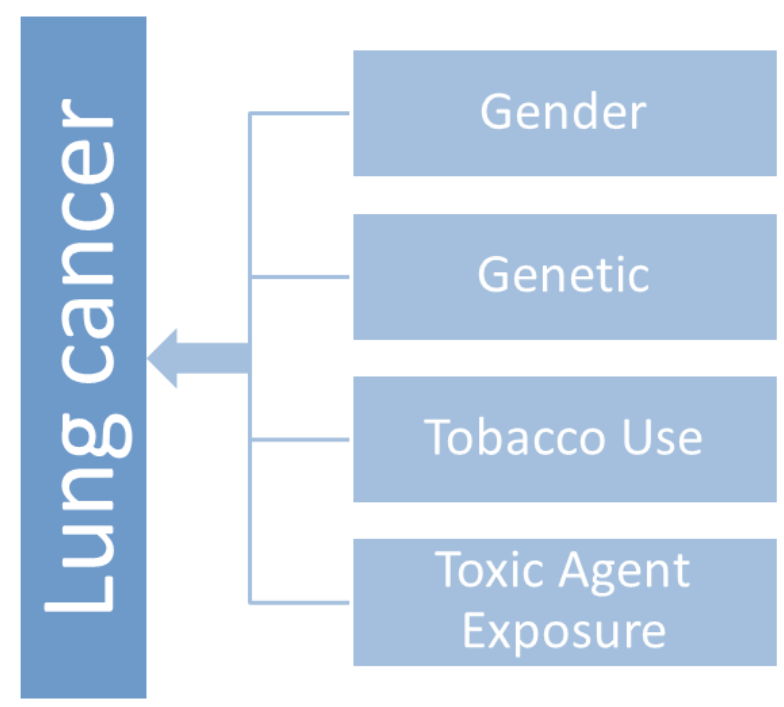

Figure 2 Risk Factors for Lung Cancer

Familial factors are also an important risk factor for lung cancer. Based on research by Malhotra et al (2016), it showed that someone who has a parent or sibling with lung cancer has a much higher risk for lung cancer than those with , parents or siblings, without lung cancer. ${ }^{16}$

Adenocarcinoma lung cancer is thought to be caused by a genetic mutation in the EGFR (epidermal growth factor receptor). Based on a study by Hea et al (2013), it was also revealed that EGFR was higher in nonsmoking women than in men who smoked and also higher in patients who had family members with a history of lung cancer than other cancers. ${ }^{18}$

Research from Samet et al (2014) showed that a smoker has a 10-30 times higher risk of developing lung cancer than a nonsmoker. This risk also applies to the 
consumption of cigarettes using pipes, cigars, and chewing tobacco. Chewing tobacco also increases the risk of mouth and throat cancer. Someone who stops smoking can reduce their risk of cancer after 5-10 years, but the risk is still higher than nonsmokers. ${ }^{19}$

Data from WHO (2011) showed that 125 million people in the world were exposed to asbestos from their workplaces and there were 107,000 deaths caused by asbestos that were thought to be related to the occurrence of lung cancer in these communities. These risks can be avoided for the health of workers and also reduce the risk of developing lung cancer. ${ }^{20}$

\section{Obesity Paradox in Lung Cancer Patients}

Research on obesity as a risk of lung cancer can be seen briefly in table 2. Yang et al (2013) conducted a meta-analysis study which can be considered as research with the highest level of evidence to answer this clinical question. The study included 31 studies with a total of 79,915,395 participants as research subjects from various studies consisting of 20 cohort studies and 11 case- control studies. Based on the meta-analysis, the RR was 0.79 (95\% confidence interval, Cl: 0.73-0.85). This study compares subjects who have a BMI of $\geq 25 \mathrm{~kg} / \mathrm{m} 2$ and a BMl of 18.5-24.9 $\mathrm{kg} / \mathrm{m}^{2}$. The study also performed calculations comparing obese patients and normal BMI patients based on the smoking status of the patients. The smoking status analysis was divided into smokers, ex-smokers, and non-smokers. The calculation of the risk of obesity in the comparison of smoking status still showed that obesity reduces the risk of lung cancer. ${ }^{21}$ Based on the meta-analysis of Yang et al (2013), it demonstrated that obesity reduced risk factors for lung cancer even though it had been controlled by smoking status.

Furthermore, it was stated in a prospective cohort study by Ardesch et al (2020) in Rotterdam, Netherlands showing that obesity has a HR: 0.94 (95\% Cl: 0.91-0.97) which can also be interpreted that obesity reduces the risk of lung cancer. However, this study is a cohort study, which has a lower level of evidence than the metaanalysis. This cohort study also compared the HR calculation for central obesity versus obesity which suggests that an increased risk of lung cancer can be seen if we measure central obesity instead of obesity based on BMI. Thus, the study concluded that measurement of central obesity based on body shape is a more important risk factor than obesity based on body size.22

\section{Discussion}

The study conducted by Yang et al (2013) was known to be the first meta-analysis study explaining the association between BMI and lung cancer risk. This study demonstrated that BMI has an inverse correlation with lung cancer risk in the general populations, this association was strengthened with smoking habits. It was also explained that smokers with low BMI tend to be prone to lung cancer compared to smokers with high BMI. This is presumably because the higher the BMI 


\begin{tabular}{|l|l|l|l|}
\hline Author (Year) & Country & Design (n) & Result \\
\hline Yang et al (2013) & China & $\begin{array}{l}\text { Meta-analysis } \\
(79.915 .395 \\
\text { participant) }\end{array}$ & $\begin{array}{l}\text { RR: 0,79 } \\
\text { (95\% Cl: 0,73-0,85) }\end{array}$ \\
\hline Ardesch et al (2020) & Netherlands & $\begin{array}{l}\text { Prospective Cohort } \\
(319)\end{array}$ & $\begin{array}{l}\text { HR:0,94 } \\
\text { (95\% Cl: 0,91-0,97) }\end{array}$ \\
\hline
\end{tabular}

Table 2. Search result study of obesity as a risk factor for lung cancer

value, the lower the level of 8-hydrodeoxyguanosine in the urine of smokers. This substance is an indicator of oxidative DNA damage in smokers. There is also another presumption about the FTO gene allele associated with increased BMI can lower the risk of lung cancer. ${ }^{21}$

Similar to the finding in the meta-analysis conducted by Yang et al (2013), Ardesch et al (2020) also demonstrated that the inverse correlation between $\mathrm{BMI}$ and lung cancer risk is associated with smoking habits. This can be explained by the accumulation of lipophilic genotoxicants such as polycyclic aromatic hydrocarbons $(\mathrm{PAH})$ in the fat tissue resulting from smoking. PAH metabolism will cause DNA damage that can lead to cancer. It was also explained that in people with high BMI, $\mathrm{PAH}$ metabolism will decrease and PAHDNA levels in the blood will also decrease, this indicates a reduced risk of lung cancer in obese people. ${ }^{22}$ Thus, further studies are needed to investigate the relationship between BMI and lung cancer in nonsmoking people.
Based on the two studies (Ardesch et al and Yang et al), we can identify the obesity paradox that occurs in lung cancer risk. A review from Marvidis et al (2019) suggested many possible biological mechanisms that might occur. One of them was discussed based on in vitro research from Nagano et al (2018) which revealed the role of the DPYSL4 gene as the gene found in obese and lung cancer patients. DPYSL4 gene is the target of the p53 gene which is a tumor suppressor gene that reduces carcinogenesis in lung cancer. The role of p53 itself is to perform apoptosis in response to DNA damage based on research by Kimura et al (2011).2325

Apart from the risk of lung cancer, various studies have also shown a paradox of obesity found in the prognosis of mortality in lung cancer patients, such as Shen et al (2017) who made a meta-analysis of a reduced risk of mortality in obese lung cancer patients with RR 0.94. $(95 \% \mathrm{Cl} 0.92-$ 0.96) with very precise figures. ${ }^{26}$ Other studies with cohort design have also shown similar results. ${ }^{27-30}$ 


\section{Conclusion}

Obesity is associated with an increased risk of various diseases. On the other hand, lung cancer which is one of the largest lung cancers in Indonesia also has various risk factors. However, various clinical research studies demonstrated that obesity reduces the risk of lung cancer, especially in smokers. Therefore, we recommend conducting further experimental studies either in clinical or laboratory about the biological mechanisms that can explain this phenomenon. Regardless of the paradoxical relationship between obesity and lung cancer, we also suggest that the public should continue to control body weight because of the risk of various diseases associated with obesity. We can also modify lung cancer risk factors by avoiding exposure to cigarettes or cigarette toxins.

\section{References}

1. Hasil utama RISKESDAS 2018. Badan Penelitian dan Pengembangan Kesehatan Kementerian Kesehatan. 2018

2. Executive summary of the clinical guidelines on the identification, evaluation, and treatment of overweight and obesity in adults. Arch Intern Med. 1998;158(17):18551867

3. International Agency for Research on Cancer. GLOBOCAN 2012: Estimated cancer incidence, mortality and prevalence worldwide in 2012. France: World Health Organization; 2012.

4. World Health Organization. Cancer: Fact sheet: World Health Organization;2015.

5. Laporan tahunan divisi onkologi toraks departemen pulmonology dan ilmu kedokteran respirasi FKUI-RSUP Persahabatan. 2015.

6. World Health Organization. World health organization-cancer country profile: indonesia. World Health Organization.;2014.

7. James PT, Leach R, Kalamara E, Shayeghi M. The worldwide obesity epidemic. Obes Res. 2001 Nov;9 Suppl 4:228S-233S.

8. WHO/IASO/IOTF . The Asia-Pacific perspective: redefining obesity and its treatment. Health Communications Australia; Melbourne: 2000.

9. Malone JI, Hansen BC. Does obesity cause type 2 diabetes mellitus (T2DM)? Or is it the opposite? Pediatr Diabetes. 2019 Feb;20(1):5-9.

10. Vekic J, Zeljkovic A, Stefanovic A, JelicIvanovic Z, Spasojevic-Kalimanovska V. Obesity and dyslipidemia. Metabolism. 2019 Mar;92:71-81.

11. Avgerinos KI, Spyrou N, Mantzoros CS, Dalamaga $M$. Obesity and cancer risk: Emerging biological mechanisms and perspectives. Metabolism. 2019 Mar;92:121135.

12. Soczynska JK, Kennedy SH, Woldeyohannes HO, Liauw SS, Alsuwaidan M, Yim CY, Mclntyre RS. Mood disorders and obesity: understanding inflammation as a pathophysiological nexus. Neuromolecular Med. 2011 Jun;13(2):93-116.

13. Saliba LJ, Maffett S. Hypertensive Heart Disease and Obesity: A Review. Heart Fail Clin. 2019 Oct;15(4):509-517.

14. Corey KE, Kaplan LM. Obesity and liver disease: the epidemic of the twenty-first century. Clin Liver Dis. 2014 Feb;18(1):1-18.

15. Lainez NM, Coss D. Obesity, Neuroinflammation, and Reproductive Function. Endocrinology. 2019 Nov 1;160(11):2719-2736. 
16. Malhotra J, Malvezzi M, Negri E, La-Vecchia C, Boffetta P. Risk factors for lung cancer worldwide. Eur Res J. 2016;10:1183

17. White MC, Holman DM, Boehm JE, Peipins LA, Grossman MS, Henley J. Age and cancer risk: a potentially modifiable relationship. Am J Prev Med. 2014;46(3S1):S7-S15.

18. Hea Y, Lb S, Rena S, Caib X, Lib X, Zhaob C, et al. Impact of family history of cancer on the incidence of mutation in epidermal growth factor receptor gene in non-small cell lung cancer patients. Lung Cancer. 2013:1-5.

19. Samet JM, Gupta PC, Ray CS, Sayvaget, C, Winn DM. Tobacco smoking and smokeless tobacco use. In: Stewar BW, Wild CP, et al. World cancer Report 2014. France: The International Agency for Research on Cancer;2014. p.88-95

20. World Health Organization. Environmental and occupational cancers: World Health Organization; 2011.

21. Yang Y, Dong J, Sun K, Zhao L, Zhao F, Wang $L$, Jiao $Y$. Obesity and incidence of lung cancer: a meta-analysis. Int J Cancer. 2013 Mar 1;132(5):1162-9.

22. Ardesch FH, Ruiter R, Mulder M, Lahousse L, Stricker BHC, Kiefte-de Jong JC. The Obesity Paradox in Lung Cancer: Associations With Body Size Versus Body Shape. Front Oncol. 2020 Nov 10;10:591110.

23. Mavridis K, Michaelidou K. The obesity paradox in lung cancer: is there a missing biological link? J Thorac Dis. 2019 Mar;11(Suppl 3):S363-S366.

24. Nagano H, Hashimoto N, Nakayama A, et al. p53-inducible DPYSL4 associates with mitochondrial supercomplexes and regulates energy metabolism in adipocytes and cancer cells. Proc Natl Acad Sci U S A 2018;115:8370-5.

25. Kimura J, Kudoh T, Miki Y, et al. Identification of dihydropyrimidinaserelated protein 4 as a novel target of the p53 tumor suppressor in the apoptotic response to DNA damage. Int J Cancer 2011;128:1524-31.

26. Shen $\mathrm{N}, \mathrm{Fu} \mathrm{P}$, Cui $\mathrm{B}, \mathrm{Bu} \mathrm{CY}, \mathrm{Bi} \mathrm{JW}$. Associations between body mass index and the risk of mortality from lung cancer: A dose-response PRISMA-compliant metaanalysis of prospective cohort studies. Medicine (Baltimore). 2017 Aug;96(34):e7721.

27. Leung CC, Lam TH, Yew WW, et al. Lower lung cancer mortality in obesity. Int J Epidemiol 2011;40:174-82.

28. Siahpush $M$, Singh $G K$, Tibbits $M$, et al. It is better to be a fat ex-smoker than a thin smoker: findings from the 1997-2004 National Health Interview Survey-National Death Index linkage study. Tobacco Control 2014;23:395-402.

29. Meyer J, Rohrmann S, Bopp M, et al. Impact of smoking and excess body weight on overall and site-specific cancer mortality risk. Cancer Epidemiol Biomarkers Prev 2015;24:1516-22.

30. Taghizadeh N, Boezen HM, Schouten JP, et al. BMI and lifetime changes in BMI and cancer mortality risk. PLoS One 2015;10.e0125261. 